Universidade Federal de Pernambuco (UFPE), Recife, PE, Brasil

¿Universidade Federal Rural de Pernambuco (UFRPE), Recife, PE, Brasil

${ }^{3}$ Programa de Pós-graduação em Biociência Animal, Universidade Federal Rural de Pernambuco (UFRPE), Rua Dom Manoel de Medeiros, $s / n$ Dois Irmãos, CEP 52171-900, Recife, PE, Brasi

* autor correspondente $\nabla$ analuporto@yahoo.com.br

\title{
Perfil dos peptídeos bioativos obtidos de queijos de coalho com potencial antimicrobiano
}

\author{
Bioactive peptides profile obtained of Coalho cheese with \\ antimicrobial potential
}

Giselle Maria Pereira Dias ${ }^{1}$, Flávio de Oliveira Silva², Tatiana Souza Porto²,

Maria Taciana Cavalcanti Holanda², Ana Lúcia Figueiredo Porto ${ }^{3 *}$

RESUMO: Os queijos contêm uma elevada quantidade de proteína e podem servir como fonte natural de peptídeos bioativos, causando diversos efeitos benéficos ao consumidor deste alimento. O objetivo do trabalho foi avaliar o perfil dos peptídeos bioativos extraídos do queijo de coalho e seu potencial antimicrobiano. Extratos de peptídeos solúveis em água foram preparados a partir de amostras de queijo de coalho artesanal produzidos com leite fresco e em seguida analisados quanto ao perfil peptídico e proteico usando técnicas proteômicas. As técnicas utilizadas incluem: (a) eletroforese em gel unidimensional (1D), (b) Cromatografia Líquida de Alta Eficiência (CLAE) e (c) Espectrometria de Massa (MS). As frações obtidas na Cromatografia Líquida de Alta Eficiência foram analisadas em gel de eletroforese, mostrando proteínas e peptídeos específicos do soro e peptídeos de caseínas. A espectrometria de massa detectou 5 peptídeos derivados da caseína $\mathrm{com} \mathrm{m} / \mathrm{z}$ variando entre 1411-1994. Três deles foram identificados como $\beta-\mathrm{CN}$ f(3-14), $\beta-\mathrm{CN}$ f(193-207) e $\beta-\mathrm{CN}$ $\mathrm{f}(193-209)$. Os extratos dos peptídeos solúveis apresentaram atividade antimicrobiana contra Bacillus subtilis ATCC 6633, enquanto as frações catiônicas, obtidas por cromatografia de troca iônica, apresentaram atividade contra Bacillus subtilis ATCC 6633 e Enterococcus faecalis ATCC 6057. Este estudo revelou a presença de dois peptídeos com m/z 1539 e 1994 não previamente identificados na literatura, podendo representar marcadores moleculares para a investigação do controle de qualidade e caracterização regional desses queijos, enquanto a atividade antimicrobiana de seus peptídeos sugere que o queijo de coalho tem potencial como alimento funcional.

PALAVRAS-CHAVE: Extrato de peptídeos solúveis, caseínas, atividade antimicrobiana.
ABSTRACT: Cheeses contain a high amount of protein and can serve as a natural source of bioactive peptides, causing many benefits to consumers. This study aimed to evaluate the profile of peptides from Coalho cheese and their antimicrobial potential. We used proteomics techniques to analyze the peptide and protein profile of extracts of water soluble peptides, prepared from Artisanal Coalho cheese produced with fresh milk. The techniques used include: (a) one-dimensional (1D) gel electrophoresis, (b) High-Performance Liquid Chromatography (CLAE), and (c) mass spectrometry (MS). We also investigated antimicrobial activities. The fractions obtained by High Performance Liquid Chromatography were analyzed by Gel electrophoresis and showed specific whey proteins and peptides from caseins. The mass spectrometry detected 5 casein-derived peptides with $\mathrm{m} / \mathrm{z}$ ranged between 1411-1994. Three of them were identified as $\beta$ - $C N f(3-14), \beta-C N f(193-207)$ e $\beta-C N$ $f(193-209)$. The water-soluble extracts showed antimicrobial activity against Bacillus subtilis ATCC 6633, while cationics fractions, obtained for ion-exchange chromatography, showed against Bacillus subtilis ATCC 6633 and Enterococcus faecalis ATCC 6057. This study revealed the presence of two peptides with $\mathrm{m} / \mathrm{z} 1539$ and 1994, new to the literature, suggesting that they may be molecular markers for investigating the quality control and regional characterization of these Coalho cheeses. The peptides antimicrobial activity suggest that Coalho cheese has potential as a functional food.

KEYWORDS: Extracts of peptides soluble, caseins, antimicrobial activity. 


\section{Introdução}

Na região Nordeste do Brasil, o queijo de coalho é mais do que um produto típico regional, constitui a principal fonte de renda da propriedade familiar do Agreste. Sua origem está ligada à fabricação artesanal, em numerosas unidades de produção caseira (QUEIROGA et al., 2013).

Muitas substâncias biologicamente ativas têm sido encontradas em diferentes tipos de queijo, inclusive no queijo de coalho. Esses peptídeos são originados pela intensa proteólise realizada por ação de enzimas exógenas e de bactérias ácido-láticas naturais durante a produção do queijo (ALMEIDA JÚNIOR et al., 2015).

Os peptídeos liberados de proteínas alimentares durante a hidrólise ou fermentação, têm despertado interesse por influenciar em numerosas respostas fisiológicas no organismo. Proteínas dos alimentos com função biológica ou efeitos fisiológicos são chamadas de peptídeos bioativos. Possuem propriedades opioides, antitrombóticas, anti-hipertensivas, antioxidantes, imunomoduladoras, antibacterianas, anti-úlceras, anti-carcinogênica e carreadora de minerais (NONGONIERMA; FITZGERALD, 2016; AKALIN, 2014).

Um número cada vez mais elevado de publicações apontam os alimentos, em especial os lácteos, como principal fonte de peptídeos com inúmeras atividades biológicas. As propriedades funcionais das proteínas do leite, do soro e de seus derivados têm atraído muita atenção devido à sua potente atividade antimicrobiana (NIELSEN et al., 2009; SILVA et al., 2012; SILVA et al., 2016; NONGONIERMA; FITZGERALD, 2016; LIMA et al., 2017).

Os peptídeos antimicrobianos geralmente possuem carga elétrica positiva (catiônicos) e são, na maioria das vezes, anfipáticos, o que capacita a molécula a ser solúvel em ambiente aquoso e facilmente inserida nas membranas lipídicas, possibilitando a morte do micro-organismo alvo. Outra propriedade desses peptídeos é a capacidade de atravessar a membrana para alcançar um alvo dentro da célula bacteriana e de distinguir células bacterianas das células de mamíferos, baseado na composição diferente dos lipídios das membranas dessas células (AROURI; DATHE; BLUME, 2009).

A pesquisa por peptídeos bioativos com atividade antimicrobiana em alimentos lácteos regionais, como o queijo de coalho, é importante para garantir uma maior valorização do produto, além de permitir o desenvolvimento da região através da agregação de valor ao produto. Além disso, o estudo do perfil de peptídeos de queijos, ou seja, a diversidade de pequenas frações proteicas originadas da hidrólise de ligações peptídicas, é um dos fatores de maior influência para a diferenciação das características sensoriais, funcionais e até tecnológicas dos produtos (FOX et al., 2015).

Neste contexto, este trabalho teve como objetivo analisar o perfil de peptídeos bioativos extraídos de queijos de coalho artesanais utilizando técnicas proteômicas, assim como avaliar seu potencial antimicrobiano.

\section{Material e Métodos}

Duas amostras de queijo de coalho artesanal foram obtidas diretamente da unidade produtora localizada no município de Cachoeirinha, Região Agreste do Estado de Pernambuco, durante os meses de março e julho do ano de 2008.
As amostras de queijos de coalho foram fabricadas usando leite cru e coalho industrial (marca HA-la). Antes da fabricação dos queijos, os leites que chegaram à unidade produtora foram submetidos aos testes de alizarol e Grau Dornic. Os leites considerados próprios para o processamento (coloração rósea e acidez entre $15-18^{\circ} \mathrm{D}$ ) foram misturados e utilizados para a fabricação dos queijos, sendo submetidos à filtração (pano de algodão), adição do coalho (proporção de $8 \mathrm{~mL} / 10 \mathrm{~L}$ ), seguido de duas mexeduras no intervalo de 20 minutos, cada. Após esse período, a massa do queijo foi prensada duas vezes. A primeira prensagem foi realizada manualmente em sacos de pano, e após a salga da massa, essa foi transferida para caixas de aço inox e prensada com um auxílio de um peso colocado sobre as formas de inox, o qual permaneceu por 60 minutos. Após esse período, os queijos foram retirados das fôrmas de inox, ensacados, coletados e armazenados a $10{ }^{\circ} \mathrm{C}$ até o momento das análises.

A extração dos peptídeos solúveis do queijo de coalho foi realizada segundo a metodologia de Gómez-Ruiz, Ramos e Recio (2002), modificada com relação à mudança na velocidade (7000xg) e tempo de rotação (20 minutos). Para essa extração, amostras de cada queijo de coalho (40 g) foram homogeneizadas com água na proporção $1: 2(\mathrm{p} / \mathrm{v})$ a $7000 x g$ por 20 minutos em homogeneizador (Nissei AM-8). Em seguida, centrifugadas três vezes a $7000 x g$ por 20 minutos, a $4{ }^{\circ} \mathrm{C}$. Após este procedimento, o sobrenadante final foi filtrado em papel de filtro quantitativo (Whatman $n^{\circ} 40$ ), liofilizado, denominado Extrato Peptídico Solúvel (EPS) e armazenado a $-20{ }^{\circ} \mathrm{C}$ até o momento das análises (realizadas em duplicata).

Os EPS do queijo de coalho foram submetidos à Cromatografia Líquida de Alta Eficiência (CLAE) em aparelho do tipo AKTA system-Amersham Pharmacia Biotech (New Jersey, USA). Como primeiro passo das análises cromatográficas, foi utilizada uma coluna de exclusão molecular tipo Superdex Peptide HR 10/30 ( $\mathrm{D}=1,0 \mathrm{~cm} \times \mathrm{C}=30,0 \mathrm{~cm})$, utilizando água ultrapura tanto como eluente das corridas cromatográficas quanto para equilibrar a coluna. $\mathrm{O}$ volume de amostra injetado foi de $0,25 \mathrm{~mL}$, o que correspondeu a uma massa de $20 \mathrm{mg}$ de proteína da amostra. Frações de $1 \mathrm{~mL}$ foram coletadas. As proteínas foram eluídas a fluxo de $0,2 \mathrm{~mL} /$ minuto.

No segundo passo, os EPS foram analisados em coluna cromatográfica de troca iônica tipo Mono Q HR 10/10 ( $\mathrm{D}=10,0 \mathrm{~cm}$ x $\mathrm{C}=10,0 \mathrm{~cm})$, sob baixa pressão, a temperatura ambiente $\left(25^{\circ} \mathrm{C}\right)$. A coluna foi equilibrada com tampão Tris- $\mathrm{HCl} 25 \mathrm{mM}, \mathrm{pH} 7,0$, e as proteínas foram eluídas isocraticamente ao fluxo de $1,0 \mathrm{~mL} /$ minuto. A fração proteica catiônica não ligada à resina foi eluída em tampão de equilíbrio, enquanto as proteínas ligadas foram eluídas no tampão de equilíbrio em gradiente de $\mathrm{NaCl}$ a $1 \mathrm{M}$, representando a fração de proteínas aniônicas. $\mathrm{O}$ volume de amostra injetado foi de $0,5 \mathrm{~mL}$, que correspondeu a uma massa de $40 \mathrm{mg}$ de proteína da amostra. Frações de 1,5 mL foram coletadas. Os pools das frações referentes aos picos foram liofilizados e armazenados para posterior análise.

Todas as análises cromatográficas foram monitoradas na absorbância de 260 e $280 \mathrm{~nm}$ através de um detector ultravioleta.

A quantificação proteica do EPS e das frações obtidas após Cromatografia Líquida de Alta Eficiência (CLAE), foi determinada segundo o método descrito por Warburg e Christian (1941). 
Os EPS do queijo de coalho, o pool dos picos obtidos por cromatografia de exclusão molecular e o pool dos picos catiônicos obtidos após cromatografia de troca iônica foram utilizados como amostra para análise do perfil eletroforético. Eletroforese em gel de poliacrilamida desnaturante (SDS-PAGE), segundo Laemmli (1970), foi constituída de um gel de separação com $15 \%$ de acrilamida: N,N'-bis-metileno acrilamida em 1,5M de tampão Tris-HCl, $\mathrm{pH} 8,8$, contendo $10 \%$ de SDS e um gel de concentração com $4 \%$ de acrilamida: N,N'-bis-metileno acrilamida em 1,5M de tampão Tris- $\mathrm{HCl}, \mathrm{pH} 6,8$. As amostras foram dissolvidas em 1,5M de tampão Tris- $\mathrm{HCl}, \mathrm{pH} 6,8$, na presença de $10 \%$ de SDS, $5 \%$ de $\beta$-mercaptoetanol e $2 \%$ de azul de bromofenol. Em seguida, aquecidas a $100^{\circ} \mathrm{C}$ por 3 minutos, e $20 \mu \mathrm{g}$ de cada amostra foram aplicadas na superfície do gel. Marcadores de alto peso moleculares (220.000-53.000 Da) e baixo peso molecular (97.000-14.400 Da) (GE Healthcare, USA) foram utilizados. A corrida foi executada a $600 \mathrm{~V}$ em corrente constante de $25 \mathrm{~mA}$ por 6 horas. Decorrido esse tempo, o gel foi corado azul de Coomassie e nitrato de prata.

O pool dos picos II obtidos através de análises em cromatografia de exclusão molecular teve suas Massas Moleculares (MM) determinadas por espectrometria de massa. As análises foram realizadas em um espectrômetro do tipo MALDI-TOF com aparelho do tipo Autoflex III (Bruker Daltonics, USA). As amostras dos extratos de peptídeos $(20 \mathrm{mg} / \mathrm{mL})$ foram diluídas em ácido trifluoroacético (TFA) a $0.1 \%(\mathrm{v} / \mathrm{v})$. Em seguida, $1 \mu \mathrm{L}$ dessa amostra diluída foi misturada com $3 \mu \mathrm{L}$ da solução matriz 4-HCCA (ácido alfa-ciano 4-hidroxicinâmico) em acetonitrila $33 \%(\mathrm{v} / \mathrm{v})$ e ácido trifluoroacético $0,1 \%(\mathrm{v} / \mathrm{v})$, operada com modo de aquisição linear positivo. A faixa de detecção foi de 800 a $3500 \mathrm{~m} / \mathrm{z}$.

A atividade antimicrobiana foi determinada pela técnica de difusão em disco, poço e determinação da Concentração Inibitória Mínima (CIM) realizada segundo normas da National Committe for Clinical Laboratory Standards (2003).

$\mathrm{Na}$ determinação da atividade antimicrobiana pela técnica de disco-difusão e poços, soluções de $300 \mathrm{mg} / \mathrm{mL}$ do EPS e de $795.5 \mu \mathrm{g} / \mathrm{mL}$ do pool catiônico obtido após cromatografia de troca iônica foram diluídas em água destilada e testados frente às bactérias Gram-positivas: Enterococcus faecalis ATCC
6057, Bacillus subtilis ATCC 6633, Staphylococcus aureus ATCC 6538, e as bactérias Gram-negativas: Escherichia coli ATCC 25922, Pseudomonas aeroginosa ATCC 27853, Klebsiela pneumoniae ATCC 29665 previamente crescida em caldo TSB (Triptic Soy Both) a $37{ }^{\circ} \mathrm{C}$ por 24 horas.

Para a técnica de disco-difusão, papéis de filtro de $5 \mathrm{~mm}$ foram embebidos nas soluções do EPS e do pool catiônico e aplicados a superfície do meio ágar Mueller Hinton. Para os testes de difusão em poços, $50 \mu \mathrm{L}$ das soluções do EPS e do pool catiônico foram adicionados em poço de $8 \mathrm{~mm}$ de diâmetro no meio ágar Mueller Hinton seguidos de incubação a $37^{\circ} \mathrm{C}$ por 24 horas. Ausência de crescimento ao redor do disco e do poço foi indicativo de inibição do crescimento.

Para a determinação da Concentração Inibitória Mínima (CIM), foram utilizadas microplacas esterilizadas de poliestireno com 96 poços. No teste foram avaliadas o EPS do queijo de coalho nas concentrações de $300,150,75,37.5,18.75,9.37$, $4.68,2.34,1.17,0.58,0.29,0.14,0.07$ e $0.03 \mathrm{mg} / \mathrm{mL}$, e o pool catiônico nas concentrações de 797.5, 398.75, 199.37, $99.68,49.84,24.92,12.46,6.23,3.11,1.55,0.77,0.38,0.19 \mathrm{e}$ $0.09 \mu \mathrm{g} / \mathrm{mL}$. A CIM foi detectável a olho nu pela ausência de turvação do meio. As amostras que não apresentaram turvação do meio foram inoculadas em placa contendo ágar nutriente e incubadas a $37^{\circ}$ por 24 horas. Após esse período, efeito bactericida foi definido pela ausência de crescimento em ágar nutriente, enquanto o efeito bacteriostático foi definido pelo crescimento do micro-organismo patogênico.

\section{Resultados e Discussão}

Os perfis cromatográficos obtidos após eluição em coluna de exclusão molecular dos EPS, na primeira e segunda coleta, apresentaram-se similares, uma vez que ambos mostraram dois picos, no mesmo tempo de retenção (Figura 1). O tempo de retenção do Pico I ocorreu a 40 minutos, enquanto o Pico II ocorreu a 90 minutos.

Os perfis cromatográficos obtidos mediante a utilização de coluna de troca iônica foram similares, na primeira e segunda coleta, apenas para fração proteica catiônica, uma vez que os peptídeos apresentaram o mesmo tempo de retenção. Enquanto
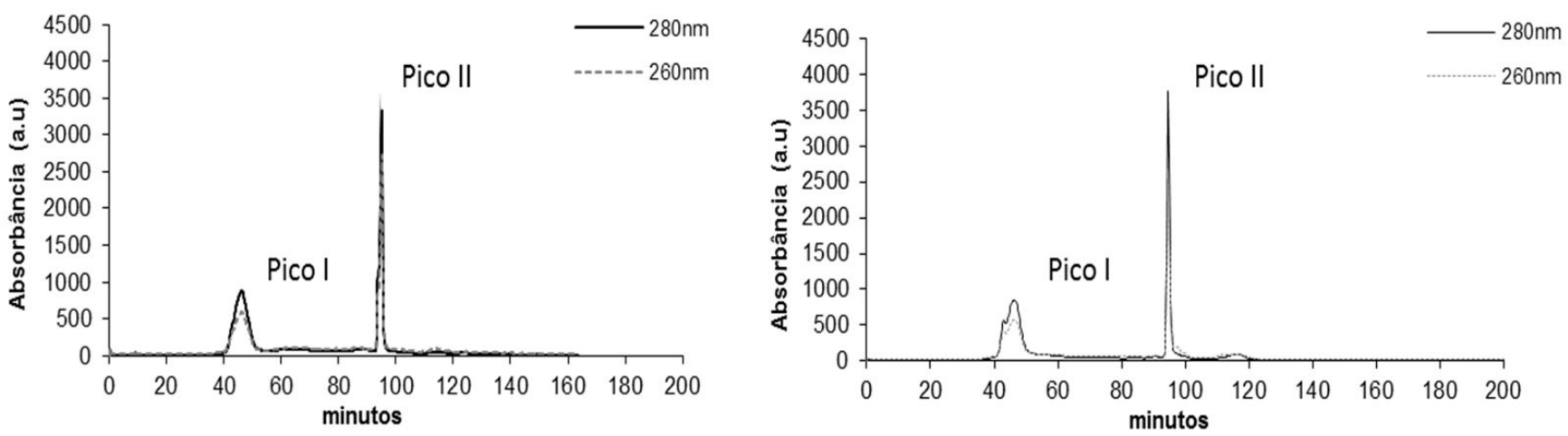

(A)

(B)

Figura 1. Perfil cromatográfico dos Extratos dos Peptídeos Solúveis (EPS) dos queijos de coalho mediante eluição em coluna Superdex Peptide HR 10/30: (A) perfil dos peptídeos extraídos do queijo da primeira coleta - março; (B) perfil dos peptídeos extraídos do queijo da segunda coleta - julho. Eluição das proteínas com água ultrapura a fluxo de $0,2 \mathrm{~mL} / \mathrm{min}$. 

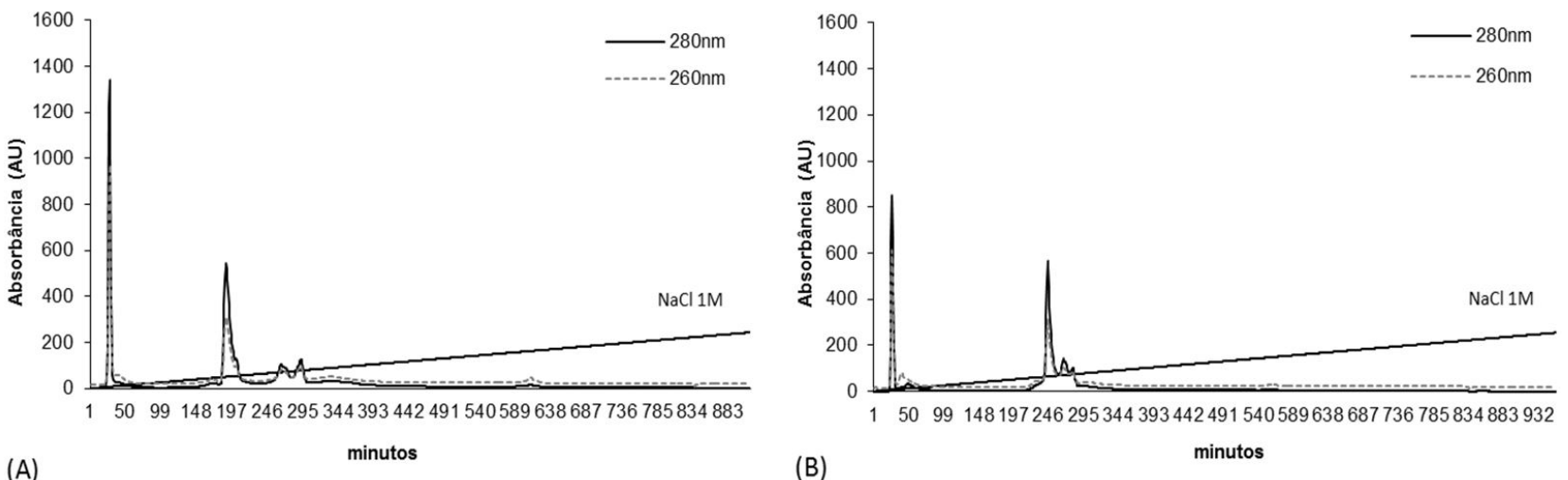

Figura 2. Perfil cromatográfico dos Extratos dos Peptídeos Solúveis (EPS) dos queijos de coalho mediante eluição em coluna de troca iônica Mono Q HR 10/10: (A) perfil dos peptídeos extraídos do queijo da primeira coleta - março; (B) perfil dos peptídeos extraídos do queijo da segunda coleta - julho. Proteínas catiônicas eluídas em $25 \mathrm{mM}$ de tampão Tris- $\mathrm{HCl}, \mathrm{pH} 7,0$ e proteínas aniônicas eluídas em $25 \mathrm{mM}$ de tampão Tris- $\mathrm{HCl}, \mathrm{pH} 7,0 \mathrm{em}$ gradiente de $\mathrm{NaCl}$ a $1 \mathrm{M}$, ambos a fluxo de $1,0 \mathrm{ml} / \mathrm{min}$., sob baixa pressão e temperatura ambiente.

a fração aniônica mostrou perfil diferente, no qual foram observados três picos que foram eluídos em diferentes tempos de retenção (Figura 2).

Os resultados do perfil eletroforético dos EPS e do pool dos picos I e II obtidos mediante eluição em coluna cromatografia de exclusão molecular estão apresentados nas Figuras 3. As análises de perfil eletroforético das proteínas do EPS do queijo de coalho (Figura 3: Linhas 2 e 3) não apresentaram alterações quanto ao número de bandas, uma vez que foi possível observar, um total de 17 bandas tanto para o EPS da primeira quanto da segunda coleta. A análise do perfil eletroforético do pool dos picos I obtidos da cromatografia de exclusão molecular (Figura 3: Linhas 4 e 5) apresentou um total de 14 e 15 bandas, para a primeira e segunda coleta respectivamente. Já o pool dos Picos II, que correspondem aos peptídeos com peso molecular entre 100-7000 Daltons (Figura 3: Linhas 6 e 7), não foram visualizados na eletroforese mesmo depois da coloração com prata, tendo suas massas moleculares e seus possíveis peptídeos identificados através de análise em espectro de massa.

As análises de perfil eletroforético do pool dos picos catiônicos obtidos após eluição em coluna catiônica (Figura 4: Linhas 4 e 5) apresentaram alterações quanto ao número de bandas, uma vez que foram visualizadas um total de 7 (Figura 4; Linha 4) e 10 bandas (Figura 4: Linha 5) para a $1^{\circ}$ a $\mathrm{e} 2^{\circ}$ a coletas, respectivamente.

As análises do perfil eletroforético mostraram que as proteínas do queijo de coalho são em sua maioria de alto peso molecular e não catiônica. As proteínas catiônicas foram predominantes na segunda coleta, apresentado um percentual de aproximadamente $59 \%$ do total de proteínas encontradas, enquanto na primeira coleta foi de $41 \%$.

A eletroforese das proteínas do EPS do queijo de coalho de Cachoeirinha (Figura 3: Linhas 2 e 3; Figura 4: Linhas 2 e 3) apresentou bandas que foram identificadas como: lactoferrina $(80 \mathrm{kDa})$, soroalbumina $(66,33 \mathrm{kDa})$, dímero de $\beta$-lactoglobulina $(36,0 \mathrm{kDa}), \alpha_{\mathrm{S} 2}$-caseína $(25,23 \mathrm{kDa}), \beta$-caseína $(23,98 \mathrm{kDa})$, $\alpha_{\mathrm{S} 1}$-caseína $(23,61 \mathrm{kDa})$, $\kappa$-caseína $(19,02 \mathrm{kDa})$; $\beta$-lactoglobulinas $(18.0 \mathrm{kDa})$ e $\alpha$-lactoalbumina $(14,2 \mathrm{kDa})$.

Todas as proteínas encontradas no EPS, também foram observadas no perfil eletroforético do pool dos picos I obtidos após cromatografia de exclusão molecular, com exceção apenas

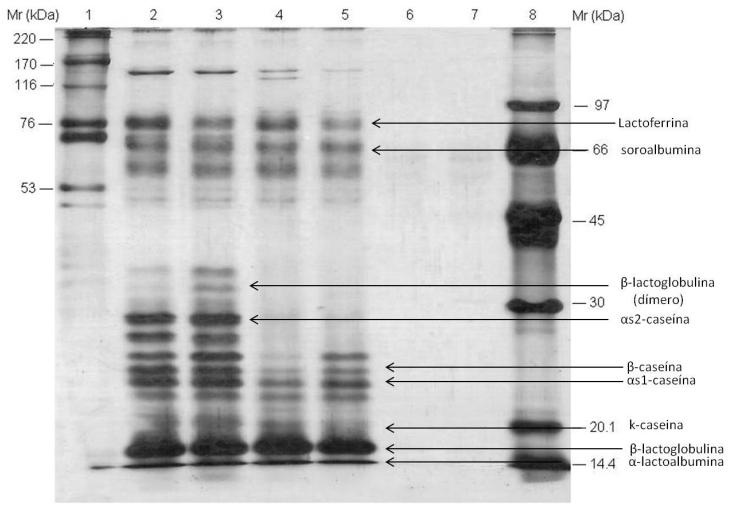

Figura 3. Eletroforese em gel de poliacrilamida SDS-PAGE do Extrato de Peptídeos Solúveis (EPS) do queijo de coalho e do pool dos picos obtido após cromatografia de exclusão molecular em coluna Superdex Peptide HR 10/30. Linha 1: padrão molecular de alto peso $(220-53 \mathrm{kDa})$; Linha 2: EPS ( $1^{\circ}$ a coleta); Linha 3: EPS ( $2^{\circ}$ a coleta); Linha 4: Pool dos Picos I ( $1^{\circ}$ a coleta); Linha 5: Pool dos Picos I ( $2^{\circ}$ a coleta); Linha 6: Pool dos Picos II ( $1^{\circ}$ a coleta); Linha 7: Pool dos Picos II ( $2^{\circ}$ a coleta); Linha 8: padrão molecular de baixo peso $(97-14,4 \mathrm{kDa})$.

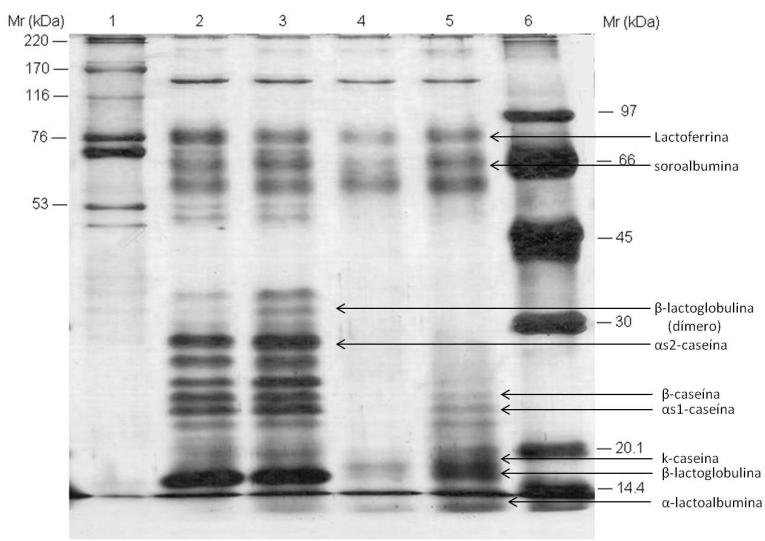

Figura 4. Eletroforese em gel de poliacrilamida SDS-PAGE dos Extratos de Peptídeos Solúveis (EPS) do queijo de coalho e do pool dos picos catiônicos obtidos após cromatografia de troca iônica em coluna Mono Q HR 10/10. Linha 1: padrão molecular de alto peso $(220-53 \mathrm{kDa})$; Linha 2: EPS ( $1^{\circ}$ a coleta); Linha 3: EPS ( $2^{\circ}$ a coleta); Linha 4: Pool dos picos catiônicos ( $1^{\circ}$ a coleta); Linha 5: Pool dos picos catiônicos ( $2^{\circ}$ a coleta); Linha 6: padrão molecular de baixo peso $(97-14,4 \mathrm{kDa})$. 
para o dímero $\beta$-lactoglobulina $(36,0 \mathrm{kDa})$, que não foi observado nem na primeira, nem segunda coleta.

As análises eletroforéticas do pool dos picos catiônicos obtidos após eluição em coluna catiônica (Figura 4: Linha 4) mostraram uma redução da quantidade de proteínas entre as coletas, observando-se apenas as proteínas lactoferrina ( $80 \mathrm{kDa})$, soroalbumina $(66,33 \mathrm{kDa}), \beta$-lactoglobulina $(18.0 \mathrm{kDa}) \mathrm{e}$ $\alpha$-lactoalbumina $(14,2 \mathrm{kDa})$ na primeira coleta, enquanto na segunda coleta (Figura 4: Linha 5) todas as proteínas presentes no EPS foram observadas, com exceção do dímero de $\beta$-lactoglobulina $(36.0 \mathrm{kDa})$ e da $\alpha_{\mathrm{S} 2}$-caseína $(25,23 \mathrm{kDa})$, que não foram observados.

As eletroforeses apresentaram bandas com massa acima de 97,4 kDa. Segundo Silva et al. (2016), proteínas com massa acima de 97,0 kDa devem-se à formação de dímeros ou à aglutinação de proteínas durante o processo de produção dos queijos. Bandas com massa abaixo de 14,0 kDa também foram observadas nas amostras do EPS da segunda coleta e na fração catiônica da primeira e segunda coletas. A presença de proteínas com massa abaixo de 14,0 kDa é resultado da proteólise que ocorre durante a maturação do queijo que praticamente não ocorre nos queijos de coalho por se tratar de um produto consumido ainda fresco (PAPPA et al., 2008).

A lactoferrina, a soroalbumina e a $\alpha$-lactoalbumina são proteínas encontradas no soro e referidas como precursoras dos peptídeos bioativos (LÓPEZ-EXPÓSITO et al., 2006). A presença de bandas que correspondiam a lactoferrina, $\beta$-lactoglobulina, $\beta$-lactoglobulina (dímero), $\alpha$-lactoalbumina, soroalbumina bovina, $\alpha$-caseína, $\beta$-caseína, k-caseína e para-k-caseína também foram observados por Silva et al. (2016), ao analisarem eletroforeticamente o perfil proteico e peptídico de extrato aquoso de queijo de coalho produzidos em diferentes cidades da Região Agreste do Estado de Pernambuco, e por Lima et al. (2017) ao investigarem se os peptídeos extraídos do queijo de coalho artesanal apresentavam atividades antimicrobiana.

Marques et al. (2005) também conseguiram separar as proteínas do soro do leite ( $\alpha$-lactoalbumina, $\beta$-lactoglobulina e soroalbumina bovina) por meio de uma coluna de exclusão molecular e afirmaram ser este um método eficaz e facilmente realizado para a separação de proteínas. Neste trabalho, esse método também permitiu a separação dessas proteínas, que podem ser facilmente visualizadas nas eletroforeses.

Pappa et al. (2008) analisaram o perfil de proteínas e peptídeos $\left(\mathrm{M}_{\mathrm{r}} 206\right.$ a 6,5 kDa) de extratos solúveis do queijo Teleme maturado por 120 dias, e também observaram na eletroforese SDS-PAGE monodimensional bandas equivalentes a soroalbumina e $\alpha$-lactoalbumina, corroborando com o presente trabalho.

Nas eletroforeses apresentadas nas Figuras 3 e 4, observa-se a presença de bandas com massa aproximada entre $\left(\mathrm{M}_{\mathrm{r}}\right) 19$ e $25 \mathrm{kDa}$ que estão presentes nos EPS (Figura 3: Linhas 2 e 3), no pools do pico I obtido por cromatografia de exclusão molecular (Figura 3: Linhas 4 e 5) e no pools catiônico da segunda coleta obtido por cromatografia de troca iônica (Figura 4: Linha 5), não sendo observada a presença dessas bandas no pools catiônico da primeira coleta. Estas bandas com massa entre 19 e $25 \mathrm{kDa}$ visualizadas no gel de eletroforese correspondem aos fragmentos de $\alpha_{\mathrm{S} 1}, \alpha_{\mathrm{S} 2}, \beta$, $\kappa$-caseína que são referidas na literatura como as principais proteínas do queijo, originadas da hidrólise da caseína pela ação da quimosina, enzima coagulante, utilizada durante a fabricação do queijo (JIN et al., 2016).

As bandas referentes aos fragmentos de $\alpha_{\mathrm{S} 1}, \alpha_{\mathrm{S} 2}, \beta$, $\kappa$-caseína foram mais intensas para as amostras referentes ao EPS do queijo de coalho (Figura 3: Linhas 2 e 3; Figura 4: Linhas 2 e 3), e foi menos intenso para o pool dos picos I obtidos por exclusão molecular da primeira coleta (Figura 3: Linha 4) e para os pool catiônicos da segunda coleta (Figura 4: Linha 5), não sendo visualizados no pool dos picos catiônicos da primeira coleta (Figura 4: Linha 4). Em todas as amostras analisadas não fora, visualizadas bandas referentes a para- $\kappa$-caseína $(\sim 11.5 \mathrm{kDa})$.

Ausência do fragmento referente a para-k-caseína e visualização dos fragmentos de $\alpha_{\mathrm{S} 1}, \alpha_{\mathrm{S} 2}, \beta$ e k-caseína também foram observados no trabalho de Egito et al. (2006), ao avaliarem por métodos eletroforéticos em gel de poliacrilamida SDS-PAGE adulteração do leite de cabra pela adição de leite de vaca. Não corroborando com os resultados apresentados por Lima et al. (2017), que visualizaram e identificaram um fragmento de para- $\kappa$-caseína obtido de extratos aquosos de queijo de coalho. A para-k-caseína $(\sim 11,5 \mathrm{kDa})$ é produto hidrolítico resultante da clivagem no fenilalanina105-Metionina106 da k-caseína durante a proteólise primária ocorrida durante a coagulação do leite através da união entre a $\beta$ e $\alpha$-caseína (HORNE, 2006).

O perfil eletroforético do pool catiônico (Figura 4: Linhas 4 e 5 ) mostrou bandas identificadas como lactoferrina $(80 \mathrm{kDa})$, soroalbumina $(66,33 \mathrm{kDa}), \beta$-caseína $(23,98 \mathrm{kDa}), \alpha_{\mathrm{S} 1}$-caseína $(23,61 \mathrm{kDa}), \kappa$-caseína $(19,02 \mathrm{kDa}) ; \beta$-lactoglobulinas $(18.0 \mathrm{kDa})$ e $\alpha$-lactoalbumina (14,2 kDa), que podem ser referidas como peptídeos catiônicos.

Fragmentos gerados por hidrólise da caseína com efeito inibitório contra o crescimento de bactérias Grampositivas e Gram-negativas também já foram referidos por Ortolani et al. (2010), Arruda et al. (2012), Silva et al. (2016) e Lima et al. (2017). Fragmentos de $\alpha_{\mathrm{S} 1}$ e $\beta$-caseína e da $\alpha$-lactoalbumina estimulam a atividade fagocitária e apresentam papel protetor contra infecções por Klebsiella pneumoniae em camundongos, podendo ainda estimular a proliferação e maturação dos linfócitos T e de células Natural killer na proteção de neonatos contra bactérias entéricas (SMACCHI; GOBBETTI, 2000). Assim, os peptídeos antimicrobianos derivados da caseína podem apresentar um controle alternativo de populações de bactérias causadoras de patologias humanas e veterinárias.

O espectro de massa evidenciou a presença de cinco diferentes peptídeos de m/z 1411, 1539, 1668, 1880 e 1994 (Figura 5) na fração de peptídeos com peso molecular entre 100 e $7000 \mathrm{Da}$ obtidos na cromatografia de exclusão molecular. Os valores m/z foram comparados com as massas moleculares de peptídeos já publicados na literatura a partir de diferentes queijos.

Dos cinco peptídeos detectados pelo espectro de massas, três são derivados de fragmentos da $\beta$-caseína. O peptídeo de $\mathrm{m} / \mathrm{z} 1668$ provavelmente corresponde a $\beta$ - $\mathrm{CN} \mathrm{f}(193-207)$, o de $\mathrm{m} / \mathrm{z} 1880$ corresponde a $\beta$-CN f(193-209), enquanto o de $\mathrm{m} / \mathrm{z} 1411$ corresponde a $\beta$-CN f(3-14). Dois peptídeos com m/z 1539 e 1994 não foram identificados previamente na literatura, 


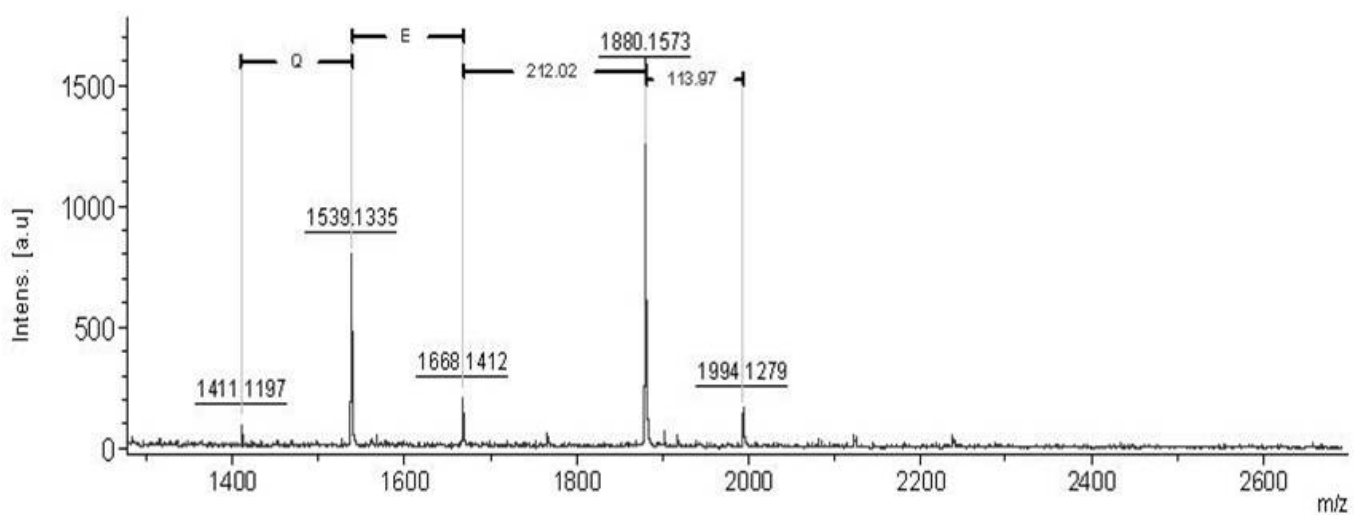

Figura 5. Espectro de massa obtido pelo MALDI-TOF das frações referentes ao pool do pico II obtidas por cromatografia de exclusão molecular do extrato peptídico solúvel (EPS) da primeira coleta. Linhas que ligam picos em sequência e as letras $(\mathrm{Q}=$ glutamina, $\mathrm{E}=$ ácido glutâmico) correspondentes à diferença de massa de um peptídeo para outro.

podendo ser incorporados como marcadores moleculares na avaliação do teste de pureza para o queijo de coalho artesanal.

O polipeptídeo $\beta-\mathrm{CN}$ f(193-209) é formado por hidrólise da $\beta$-caseína promovida pela ação da quimosina que atua clivando a ligação Leu $_{192}-$ Tyr $_{193}$ (BAPTISTA et al., 2017). Enquanto o peptídeo $\beta$-CN f(3-14) pode ser obtido do trato gastrointestinal humano após a ingestão de leite ou produtos lácteos (NONGONIERMA; FITZGERALD, 2016).

A utilização de técnica de espectrometria também permitiu a identificação de fragmentos da $\beta$-caseína em queijo Emmental (GAGNAIRE et al., 2001), em queijo cheddar (SOERYAPRANATA et al., 2002), em queijo stilton (PIRAINO et al., 2007) em queijo de coalho (SILVA et al., 2016; LIMA et al., 2017) e em queijo prato (BAPTISTA et al., 2017).

$\mathrm{Na}$ figura 5 é possível observar linhas que ligam picos em sequência e letras $(\mathrm{Q}=$ glutamina; $\mathrm{E}=$ ácido glutâmico) que significam resíduos de aminoácidos correspondentes à diferença de massa de um peptídeo a outro. Assim, o peptídeo de m/z 1411 difere do peptídeo de m/z 1539 pela presença do aminoácido glutamina $(Q)$, enquanto que esse difere do peptídeo de m/z 1668 apenas pelo resíduo de ácido glutâmico (E). Ainda pode ser observada na Figura 5, a diferença de m/z de um peptídeo a outro foi de 212,02 e 113,97.

Os polipeptídeos da $\beta$-caseína identificados neste trabalho apresentam sequência de aminoácidos e bioativiadade conhecida na literatura. Os polipeptídeos da $\beta-\mathrm{CN} f(193-209), \beta-\mathrm{CN}$ f(193-207) e $\beta$-CN f(3-14) apresentam sequências de aminoácidos ${ }^{193}$ YQEPVLGPVRGPFPIIV ${ }^{209},{ }^{193}$ YQEPVLGPVRGPFPI ${ }^{207}$ e ${ }^{3}$ LEELNVPGEIVE $^{14}$ respectivamente (NONGONIERMA; FITZGERALD, 2016; LOPEZ-EXPÓSITO; AMIGO; RECIO, 2012). Contudo, apenas os fragmentos de resíduos de aminoácidos de 193-209 e de 193-207 têm bioatividade conhecida exibindo atividade antimicrobiana, imunomodulatória e inibitória da Enzima Conversora de Angiotensina (ECA) (NONGONIERMA; FITZGERALD, 2016).

Quanto à atividade antimicrobiana, Bacillus subtilis ATCC 6633 foi o único microrganismo sensível à ação do EPS e ao pool das frações catiônicas em todos os ensaios realizados, uma vez que apresentou média de halos de inibição de 5,25 mm e 3,75 mm para a técnica de difusão em poços e disco-difusão, respectivamente.

A concentração inibitória mínima capaz de inibir o crescimento de Bacillus subtilis ATCC 6633 foi de 9,37 mg/ mL para o EPS e de 6,22 $\mu \mathrm{g} / \mathrm{mL}$ para o pool da fração catiônica. Ainda, o pool da fração catiônica foi capaz de inibir o crescimento de Enterococcus faecalis ATCC 6057 na concentração inibitória mínima de 199,37 $\mu \mathrm{g} / \mathrm{mL}$.

A inibição do crescimento de Bacillus subtilis e Enterococcus faecalis por peptídeos do queijo de coalho é fator importante na sanidade do produto e impedem que essas bactérias assumam importância clínica por serem consideradas como patógenos oportunistas (HERNÁNDEZ-LEDESMA et al., 2014). Os resultados deste trabalho corroboram com os apresentados por Silva et al. (2012) e Arruda et al. (2012), que identificaram peptídeos resultantes da hidrólise da caseína capaz de inibir a ação de Bacillus subtilis e Enterococcus faecalis.

\section{Conclusão}

A presença de peptídeos com capacidade de inibir o crescimento de Bacillus subtilis e Enterococcus faecalis confirmam a bioatividade desses peptídeos, podendo reduzir a contaminação, aumentar o prazo de validade além de agregar valor a esse produto regional.

\section{Referências}

AKALIN, A. S. Dairy-derived antimicrobial peptides: Action mechanisms, pharmaceutical uses and production proposals. Trends in Food Science \& Technology, London, v. 36, n. 2, p. 79-95, 2014.

ALMEIDA JÚNIOR, W. L. G. et al. Characterization and evaluation of lactic acid bacteria isolated from goat milk. Food Control, Vurrey, v. 53, p. 96-103, 2015. 
AROURI, A.; DATHE, M.; BLUME, A. Peptide induced demixing in PG/PE lipid mixtures: A mechanism for the specificity of antimicrobial peptides towards bacterial membranes. Biochimica et Biophysica Acta, Amsterdam, v. 1788, n. 3, p. 650-659, 2009.

ARRUDA, M. S. et al. New peptides obtained by hydrolysis of caseins from bovine milk by protease extracted from the latex Jacaratia corumbensis. LWT - Food Science and Technology, Amsterdam, V. 49, n. 1, p. 73-79, 2012.

BAPTISTA, D. P. et al. A Survey of the Peptide Profile in Prato Cheese as Measured by MALDI-MS and Capillary Electrophoresis. Journal of Food Science, New Jersey, v. 82, n. 2, p. 386-393, 2017.

EGITO, A. S. et al. Método eletroforético rápido para a detecção da adulteração do leite caprino com leite bovino. Arquivo Brasileiro de Medicina Veterinária e Zootécnica, Belo Horizonte, v. 58, n. 5, p. 932-939, 2006.

FOX, P. F. et al. Dairy chemistry and biochemistry. 2nd ed. Berlin: Springer International Publishing, 2015, 184 p.

GAGNAIRE, V. et al. Peptides identified during emmental cheese ripening: origin and proteolytic systems involved. Journal of Agricultural and Food Chemistry, United States, v. 49, n. 9, p. 4402-4413, 2001

GÓMEZ-RUIZ, J. A.; RAMOS, M.; RECIO, I. Angiotensin-converting enzyme-inhibitory peptides in Manchego cheeses manufactured with different starter cultures. International Dairy Journal, Amsterdam, V. 12, n. 8, p. 697-706, 2002.

HERNÁNDEZ-LEDESMA, B. et al. Dairy protein hydrolysates: peptides for health benefits. Internacional Dairy Journal, Amsterdam, v. 38, n. 2, p. 82-100, 2014.

HORNE, D. S. Casein micelle structure: Models and muddles. Current Opinion in Colloid \& Interface Science, Copenhagen, v. 11, n. 2-3, p. 148-153, 2006.

JIN, Y. et al. Peptide profiling and the bioactivity character or yogurt in the simulated gastrointestinal digestion. Journal of Proteomics, Valencia, v. 141, p. 24-46, 2016.

LAEMMLI, U. K. Cleavage of structural proteins during the assembly of head of bacteriophage $\mathrm{T}_{4}$. Nature, United Kingdom, v. 227, n. 5259, p. 680-685, 1970.

LIMA, M. S. F. et al. Queijo de Coalho artesanal: fonte alternativa de peptídeos antimicrobianos. Brazilian Journal of Food Technology, Campinas, v. 20, n. 0, p. 1-7, 2017

LÓPEZ-EXPÓSITO, I.; AMIGO, L.; RECIO, I. A mini-review on health and nutritional aspects of cheese with a focus on bioactive peptides. Dairy Science \& Technology, Paris, v. 92, n. 5, p. 419-438, 2012.

LÓPEZ-EXPÓSITO, I. et al. Identification of antibacterial peptides from bovine kappacasein. Journal of Food Protection, China, v. 69, n. 12, p. 2992-2997, 2006.
MARQUES, D. P. et al. Separação das proteínas do soro do leite por DEAE-TRISACRYL. Alimentos e Nutrição, Campinas, v. 16, n. 1, p. 17-20, 2005.

NATIONAL COMMITTE FOR CLINICAL LABORATORY STANDARDS - NCCLS. Methods for dilution antimicrobial susceptibility tests for bacteria that grow aerobically. Pennsylvania: NCCLS, 2003. p. 1887-1898. NCCLS document M7-A6.

NIELSEN, M. S. et al. Peptide profiles and angiotensin-I-converting enzyme inhibitory activity of fermented milk products: Effect of bacterial strain, fermentation $\mathrm{pH}$, and storage time. International Dairy Journal, Netherlands, v. 19, n. 3, p. 155-165, 2009.

NONGONIERMA, A. B.; FITZGERALD, R. J. Strategies for the discovery, identification and validation of milk protein-derived bioactive peptides. Trends in Food Science \& Technology, London, v. 50, p. 26-43, 2016.

ORTOLANI, M. B. T. et al. Molecular identification of naturally occurring bacteriocinogenic and bacteriocinogenic-like lactic acid bacteria in raw milk and soft cheese. Journal of Dairy Science, Amsterdam, v. 93, n. 7, p. 2880-2886, 2010.

PAPPA, E. C. et al. Application of proteomic techniques to protein and peptide profiling of Teleme Cheese made from different types of milk. International Dairy Journal, Netherlands, v. 18, n. 6, p. 605-614, 2008.

PIRAINO, P. et al. Use of mass spectrometry to characterize proteolysis in cheese. Food Chemistry, Barking, v. 101, n. 3, p. 964-972, 2007.

QUEIROGA, R. C. R. E. et al. Nutritional, textural and sensory properties of Coalho cheese made of goats', cows' milk and their mixture. LWT- Food Science and Technology, Amsterdam, v. 50, n. 2, p. 538-544, 2013.

SILVA, R. A. et al. Can artesanal "Coalho" cheese from Northeastern Brazil be used as a functional food? Food Chemistry, Barking, v. 135, n. 3, p. 1533-1538, 2012.

SILVA, R. A. et al. Proteomic and peptidomic profiling of Brazilian artisanal 'Coalho' cheese. Journal of the Science of Food and Agriculture, EUA, v. 96, n. 13, p. 4337-4344, 2016.

SMACCHI, E.; GOBBETTI, M. Bioactive peptides in dairy products: synthesis and interaction with proteolytic enzymes. Food Microbiology, Cambridge, v.17, n.2, p. 129-141, 2000

SOERYAPRANATA, E. et al. Relationship between MALDI-TOF analysis of $\beta-C N$ f193-209 concentration and sensory evaluation of bitterness intensity of aged Cheddar cheese. Journal of Agricultural and Food Chemistry, Washington, v. 50, n. 17, p. 4900-4905, 2002.

WARBURG, O.; CHRISTIAN, W. Isolierung und kristallisation des granges ferments enolase. Die Naturwissenschaften, Germany, v. 29 , n. 39, p. 589-590, 1941. 